\title{
Enhancing appropriateness of acute bed use: role of the patient hotel
}

\author{
Ian Harvey, Rosemary Jenkins, Lise Llewellyn
}

\begin{abstract}
Objective-This study aimed to assess the appropriateness of bed use by determining patients' suitability for patient hotel accommodation and day treatment and by examining timeliness of discharge, and to assess patient and staff views about patient hotels. Design-Patients were assessed by a doctor and nurse in terms of an agreed case definition for patient hotel use. Patient suitability was validated and patient acceptability measured by semi-structured interviews with a random sample of patients judged suitable for hotel accommodation. All senior medical and nursing staff completed a further questionnaire.

Setting-The study took place at University Hospital of Wales, Cardiff ( 856 beds), and all specialties, except intensive care wards, participated.
\end{abstract}

Subjects-Patients occupying a total of 3972 bed days, accumulated over seven randomly chosen census days, were studied.

Results-Data were available for $88 \%$ of eligible inpatients. Ten per cent (405 of 3972) of patients were judged suitable for a patient hotel. Specialties indicating major use were obstetrics and gynaecology, general surgery, and general and geriatric medicine. Sixty three per cent (254 of 405 ) of these subjects required low level investigation or treatment. Preoperative and postoperative and antenatal patients were often suitable also. Three per cent (119 of $3972,95 \%$ confidence interval $2 \cdot 5,3 \cdot 6 \%$ ) of inpatients were judged suitable for day treatment/investigation. Seventy nine per cent (291 of 369) of patients suitable for discharge were discharged on the same or the next day. The patient hotel idea was acceptable to 58 of $68(85 \%)$ randomly selected patients and to 84 of $93(90 \%)$ staff. Conclusions-With allowance for nonresponse, our study indicates that a general hospital of this size generates the need (inpatients, relatives, and ward attenders) for a mean of 72 patient hotel beds. There is also residual scope for increasing day treatment/investigation and for releasing beds by speeding discharge. The patient hotel idea is highly acceptable to both patients and staff and should be widely considered as a means of making patient care more efficient.

f Epidemiol Community Health 1993; 47: 368-372

Studies over a number of years have indicated that only a relatively low proportion of bed days in acute hospitals in the UK are used appropri- ately. ${ }^{1-4}$ Other models of provision for patients have been proposed, ${ }^{5}$ prominent among which have been patient hotels. ${ }^{6-9}$ These have existed for several years in Sweden and the United States. ${ }^{10}$ 12 They are typically separate buildings adjacent to acute hospitals that provide good quality (AA 3 star) accommodation for mobile patients who can care for themselves and control their own medication. They are frequently run by a private sector organisation. Patients must attend the hospital for almost all medical and nursing interventions, although qualified nurses are often employed as hotel receptionists. Many National Health Service providers are currently considering establishing free-standing patient hotels. The Audit Commission ${ }^{10}$ has suggested that $15 \%$ of patients in acute units at any one time may be suitable and that, in all, one third of medical beds may be superfluous. Another estimate is that between $5 \%$ and $15 \%$ of patients may be suitable for a patient hotel. ${ }^{6}$ There has not hitherto been any published validation of these estimates, however, to guide those intending to plan or contract for such facilities. This study, undertaken in a large teaching hospital (University Hospital of Wales, Cardiff, 856 inpatient beds) which provides both district general hospital and regional functions, reports on the number of suitable patients and also investigates the attitudes of both patients and staff. It was commissioned by the local health authority to provide essential information for fully informed negotiations with hotel operators but has wide implications for other hospitals in the United Kingdom and elsewhere.

\section{Methods and subjects}

CASE DEFINITION

An operational policy was drafted by the research team and was modified and approved by a steering group consisting of senior consultants, nurses, and managers. The policy drew on published and commercial reports relating to patient hotels. It outlined the likely available facilities and proposed a case definition of a suitable patient as follows:

"Suitable patients are entirely self-caring, mobile and able to manage their own medication and either need to be resident for at least one night on the hospital site (eg are receiving intermittent low-level therapy or investigations and cannot be expected to travel in on a daily basis) or having recently required acute care are awaiting planned discharge and cannot go elsewhere in the meantime."

It was proposed that the length of stay should not normally exceed five days and that patients would receive any nursing or medical interventions in the main hospital. Relatives of inpatients were also eligible to use the hotel, but a charge would be made. The possible use of the hotel by 
the paying general public was raised by the health authority and was included in the draft policy. The hotel would potentially be available for all specialties. Copies of the operational policy and case definition were sent to all consultants and ward sisters. A presentation was given to the hospital management board and to as many clinical directorates as possible.

PATIENT ASSESSMENT QUESTIONNAIRE

A 12 item questionnaire was developed, to be completed for each patient. This was structured so that patients who had been admitted as planned day cases were first identified and data collection terminated. Each remaining patient was considered for suitability for either day case treatment or for discharge to their normal place of residence. Only then was patient hotel suitability considered. The purpose of this process was to ensure that patient hotel accommodation was not seen as the only alternative to inpatient accommodation. In particular, the patient hotel should not become an inappropriate alternative to efficient discharge , arrangements for the elderly. It was also emphasised that the judgements required related to the patient's condition on that day. The questionnaire was piloted on 79 patients from four specialties. The consultant and a senior nurse caring for each patient were asked to share clinical information and each complete a questionnaire independently of the other so that interobserver reliability could be assessed. The questionnaire was subsequently modified slightly, and, in view of the satisfactory level of agreement between observers (see below), during the main study doctors and nurses were asked to arrive at a consensus view and complete only one questionnaire per patient. This reduced the workload and improved the response rate.

\section{CENSUS DAYS}

Seven census days were held during March and April 1992. Days were selected randomly, with the constraints that each day of the week (including weekends) should be represented once, there would be no more than one census day in any one week (Sunday to Sunday), and bank holidays were excluded. On each census day every inpatient (with the exception of those in intensive care/high dependency, coronary care, bone marrow transplant unit, special care baby unit, and the day unit) was assessed by a doctor familiar with the patient (where possible the consultant) and a senior nurse.

\section{VALIDATION AND PATIENTS' VIEWS}

Ten patients randomly selected from those who had been assessed as suitable for the hotel were interviewed by one of two researchers on each census day (total 70) using a semistructured schedule. This was preceded by a short, neutrally worded explanation of the patient hotel concept. This exercise was undertaken to ascertain patients' views and also allowed a medically qualified member of the research team (LL) to validate the judgements about suitability. On the basis of the pilot results (where none of the 32 selected patients were judged unsuitable) it was concluded that 70 subjects would give acceptably narrow confidence intervals for the proportion of selected patients unsuitable for the hotel. Local research ethics committee approval was obtained for this phase of the study.

\section{RELATIVES AND WARD ATTENDERS}

Each ward sister was asked on each day to estimate the number of relatives and ward attenders (those attending on a daily basis for treatment/ investigation and not counted as a day case) who would have required hotel accommodation that night.

\section{PATIENTS SUITABLE FOR DISCHARGE}

As a subsidiary objective of the study, patients who were judged suitable for discharge at assessment were tracked using the district computerised patient administration system to determine the time that elapsed before discharge actually occurred. This was not done until three months after the last census day to allow a generous margin of time for the whole cohort to be discharged. Clinicians remained unaware that this was being done in order to minimise response bias.

\section{STAFF VIEWS}

Two months after completion of the main study, a summary of the findings was circulated to all consultants, senior registrars, and ward sisters, together with an eight item questionnaire. This sought information about staff attitudes towards a mixture of general and specific aspects of the patient hotel. A second questionnaire was sent to non-responders followed by a telephone reminder.

\section{DATA ANALYSIS}

Data were entered and analysed using SPSS-PC version 4. Confidence intervals were calculated using Confidence Interval Analysis Version 1.0 (Gardner MJ and SB, Winter PD. British Medical Journal, 1991). Cohen's kappa statistic was used to represent the extent of interobserver agreement beyond chance. ${ }^{13}$

\section{Results}

PILOT

Interobserver agreement for three key assessments performed on 79 pilot subjects (suitability for day treatment; suitability for discharge; suitability for patient hotel) was $95 \%, 79 \%$, and $80 \%$ respectively (Cohen's kappa values: $0.64,0.32$, and 0.58 ).

\section{MAIN STUDY}

The mean bed occupancy in the ward areas covered by the study during the seven census days was $82 \%$ (mean 645 occupied of 787 available). Of the 4515 occupied bed days available to the study, satisfactory data were available for $88 \%$. Daily response rates varied from $96.6 \%$ (605 of 626 ) on the Sunday to $74.5 \%$ ( 516 of 693 ) on the Monday. Specialty response rates varied from $57 \%$ (66 of 115 ) in ear, nose, and throat to $98.9 \%$ (533 of 539) in obstetrics and gynaecology. Nonresponse was principally due to administrative error, particularly the mislaying of blank questionnaires by ward staff, which is unlikely to lead to serious bias in the estimates made.

The doctor involved in the assessment was from the clinical team responsible for the patient in $62 \%$ (1515) of the 2437 cases for which this 
Table I Patient assessment results

\begin{tabular}{lcccccc}
\hline Day & $\begin{array}{c}\text { Patients } \\
\text { assessed }\end{array}$ & $\begin{array}{c}\text { No (\%) suitable } \\
\text { for day treatment }\end{array}$ & $\begin{array}{c}\text { No (\%) suitable } \\
\text { for discharge }\end{array}$ & $\begin{array}{c}\text { No (\%) suitable } \\
\text { for patient hotel }\end{array}$ & $\begin{array}{l}\text { No relatives for } \\
\text { patient hotel }\end{array}$ & $\begin{array}{l}\text { No daily ward } \\
\text { attenders for } \\
\text { patient hotel }\end{array}$ \\
\hline 1 Tuesday & 621 & $23(3 \cdot 7)$ & $81(13)$ & $72(11 \cdot 6)$ & 21 & 2 \\
2 Friday & 556 & $23(4 \cdot 1)$ & $75(13 \cdot 5)$ & $63(11 \cdot 3)$ & 9 & 0 \\
3 Monday & 516 & $19(3 \cdot 7)$ & $54(10 \cdot 5)$ & $50(9 \cdot 7)$ & 13 & 2 \\
4 Thursday & 574 & $16(2 \cdot 8)$ & $63(11 \cdot 0)$ & $59(10 \cdot 3)$ & 2 & 0 \\
5 Sunday & 605 & $11(1 \cdot 8)$ & $26(4 \cdot 3)$ & $76(12 \cdot 6)$ & 14 & 5 \\
6 Saturday & 548 & $7(1 \cdot 3)$ & $43(7 \cdot 8)$ & $39(7 \cdot 1)$ & 15 & 6 \\
7 Wednesday & 552 & $20(3 \cdot 6)$ & $72(13 \cdot 0)$ & $46(8 \cdot 3)$ & 6 & 12 \\
Total & 3972 & $119(3 \cdot 0)$ & $414(10 \cdot 4)$ & $405(10 \cdot 2)$ & 80 & \\
\hline
\end{tabular}

information was available. In other cases another clinical team was involved, and in only 13 cases was the questionnaire completed by a nurse alone.

The proportions of patients suitable for day treatment/investigation, discharge, and for patient hotel accommodation are shown in table I for each census day. The overall proportion judged suitable for a patient hotel is $10 \cdot 2 \%(95 \%$ confidence interval (CI): $9 \cdot 311 \cdot 1 \%$ ). Table II shows, for each specialty, the probability of an assessed patient being suitable for the patient hotel. Table III shows the probability of suitability for patient hotel accommodation according to time elapsed since admission, for selected specialties. This profile varies considerably between the four main specialty users. A high proportion of long stay (greater than 10 days) obstetrics and gynaecology patients (mainly antenatal patients) were judged suitable for the patient hotel. The prior expectation, that a high proportion of longer stay geriatric patients might be selected, was not confirmed.

\section{PROFILE OF HOTEL USERS}

The likely major specialty users of the hotel (table II) are obstetrics and gynaecology, general surgery, general medicine and geriatric medicine. The age and sex profile of these patients is shown in table IV. Forty four per cent (171 of 387 (18 missing)) were originally admitted as emergencies. Residents from outside the host district (South Glamorgan) constituted 32\% (129 of 405) of potential users.

The reasons given for requiring patient hotel accommodation are shown in table $\mathrm{V}$ (more than one reason was permitted per patient), from

Table II Patient hotel suitability in relation to specialty group

\begin{tabular}{lcccc}
\hline & & \multicolumn{3}{c}{$\%$ Suitable for patient hotel $(95 \%$ CI) } \\
\cline { 4 - 5 } Specialty & Assessments & Lower limit & Point estimate & Upper limit \\
\hline General Surgery & 628 & $15 \cdot 1$ & $18 \cdot 2$ & $21 \cdot 2$ \\
Obstetrics Gynaecology & 533 & $15 \cdot 4$ & $18 \cdot 8$ & $22 \cdot 1$ \\
General medicine (including clinical & 592 & $6 \cdot 2$ & $8 \cdot 3$ & $10 \cdot 8$ \\
genetics and rheumatology & & & & \\
Paediatrics & 298 & $4 \cdot 7$ & $7 \cdot 4$ & $11 \cdot 0$ \\
Urology & 176 & $4 \cdot 9$ & $8 \cdot 5$ & $13 \cdot 7$ \\
Geriatric medicine & 680 & $4 \cdot 0$ & $5 \cdot 6$ & $7 \cdot 6$ \\
Ophthalmology & 79 & $10 \cdot 0$ & $17 \cdot 7$ & $27 \cdot 9$ \\
Cardiology/cardiothoracic surgery & 315 & $5 \cdot 2$ & $7 \cdot 9$ & $11 \cdot 5$ \\
Neurology/neurosurgery & 274 & $4 \cdot 2$ & $6 \cdot 9$ & $10 \cdot 6$ \\
ENT/oral surgery & 71 & $0 \cdot 9$ & $4 \cdot 2$ & 11.9 \\
Haematology & 80 & 0 & 0 & $4 \cdot 5$ \\
Dermatology & 133 & $1 \cdot 7$ & $4 \cdot 5$ & $9 \cdot 6$ \\
Psychiatry & 113 & 0 & 0 & $3 \cdot 2$ \\
Total & 3972 & $9 \cdot 3$ & $10 \cdot 2$ & $11 \cdot 1$ \\
\hline
\end{tabular}

ENT=ear, nose, and throat

Table III Percentage (no) suitable for patient hotel in relation to length of stay for major specialty users

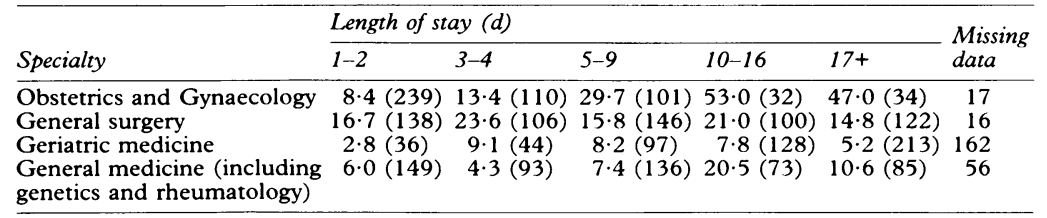

which it may be seen that almost two thirds required low level monitoring or simple investigations. Only a few were awaiting assessment or finalisation of discharge arrangements.

Respondents were asked to indicate the anticipated length of stay of each patient in the hotel. The median anticipated stay was $2 \cdot 4$ days (range 1-94). In $13 \cdot 5 \%$ (45 of 334 (71 missing values)) of cases, however, the projected stay exceeded the five days suggested in the operational policy. Those completing the questionnaires were asked if their judgement of suitability for the patient hotel would have been reversed if the hotel was open to the general public. Fifteen per cent (43 of 281, 122 missing values) indicated that their decision would have been reversed.

On a six point Likert type scale (extremes defined as: very confident and very uncertain) only 12 of $399(4 \%)$ respondents indicated any degree of uncertainty in their assessment decision.

Table IV Age and sex profile of patient hotel users

\begin{tabular}{lccc}
\hline Age $(y)$ & Male & Female & Total \\
\hline $0-9$ & 10 & 8 & 18 \\
$10-19$ & 5 & 6 & 11 \\
$20-29$ & 7 & 36 & 43 \\
$30-39$ & 9 & 36 & 45 \\
$40-49$ & 13 & 26 & 39 \\
$50-59$ & 24 & 25 & 49 \\
$60-69$ & 32 & 30 & 62 \\
$70-79$ & 32 & 40 & 72 \\
$80+$ & 16 & 50 & 66 \\
Total & 148 & 257 & 405
\end{tabular}

Table $V$ Reasons for requiring hotel accommodation in 405 suitable patients (More than one reason was permitted per patient)

\begin{tabular}{lrl}
\hline Reason & No & $\begin{array}{l}\% \text { Of suitable subjects } \\
\text { in which mentioned }\end{array}$ \\
\hline Low level monitoring & 254 & 63 \\
$\quad$ or investigation & 72 & 18 \\
Before surgery & 96 & 24 \\
After surgery & 28 & 7 \\
Antenatal & 15 & 4 \\
Postnatal & 24 & 6 \\
Social work/occupational & 13 & 3 \\
$\quad$ therapy assessment & 8 & 2 \\
Awaiting residential home & & \\
Awaiting transport/ & nursing arrangements & 5 \\
Other reasons & 21 & 5
\end{tabular}

VALIDATION AND PATIENTS' VIEWS

Sixty eight patients out of 70 randomly selected from those had had been assessed as suitable for the hotel were willing to be further assessed by a medically qualified member of the research team (LL) on the same day. Seven $(10 \cdot 3 \%, 95 \%$ CI $4 \cdot 2$, $20 \cdot 1 \%$ ) were judged to be probably or definitely unsuitable, mainly because of inadequate mobility.

The same 68 patients were asked to select responses on six point Likert scales after a standard, neutrally worded explanation of the patient 
hotel had been given. Eighty five per cent ( 58 of 68 ) would have been very, quite or reasonably happy to have spent part of their stay in such a hotel. Twenty five per cent (17 of 68) were unhappy to some degree, however, at the possibility of the paying general public making use of the hotel. Reasons given were concern about privacy, security, and risk of infection. Twenty four per cent (16 of 68) considered that a relative would have wished to stay in the hotel. It was made clear that this, unlike the patient's own stay, would involve a charge.

\section{STAFF VIEWS}

Ninety seven of 128 staff members responded $(75 \cdot 8 \%)$. Eighty five per cent ( 80 of 94 ) had been aware of the patient assessment exercise. Only $10 \%$ (nine of 93 ) expressed any opposition to the idea of a patient hotel but 58 of $93(62 \%)$ were opposed to use of the hotel by the general public. Sixty two per cent ( 56 of 91 ) of all respondents ( 37 of $43(80 \%)$ of consultants) indicated they would probably or definitely use the hotel for patients who could care for themselves. In response to the following question- "the patient hotel may be seen as part of a general trend towards the development of smaller acute hospitals containing a higher proportion of critically ill patients. How do you feel about this?", 14 of $47(30 \%)$ consultants expressed some degree of opposition.

\section{PATIENTS SUITABLE FOR DISCHARGE}

The residual length of stay could be computed for 369 of 414 patients judged suitable for discharge $(89 \%)$. Seventy nine per cent (291 of 369$)$ were discharged either on the same or the following day, but 61 of $369(16.5 \%)$ were not discharged until between two and seven days later. The maximum delay was 36 days.

\section{PATIENT HOTEL BED NUMBERS}

Each census day estimate of the number suitable for the patient hotel may be factored up to allow for incomplete response (see table VI). In doing so it is assumed that responders represent an unbiased sample of the total group. This number should then be reduced to allow for the findings of the validation exercise, that $10 \cdot 3 \%(95 \%$ CI $4 \cdot 2$, $20 \cdot 1 \%$ ) of subjects were unsuitable. To these patients must be added relatives and ward attenders. The final column shows the day to day variation (and the error due to sampling) in the number of suitable individuals.

\section{Discussion}

Although two NHS trusts have recently opened hospital hotel accommodation (Kingston upon
Thames and St Mary's, Paddington), it is clear from their operational policies that they are targetting more dependent patients by providing assistance, where necessary, in activities of daily living. Nor has a quantitative assessment of need preceded their establishment. As a consequence they are smaller ( 16 beds and 15 beds) than our study suggests is necessary.

From a methodological standpoint, the interobserver agreement (reliability) found during the piloting of the assessment questionnaire was better than that reported in most settings requiring clinical judgement, such as the interpretation of radiographs, the identification of clinical signs, or the assessment of quality of care. ${ }^{14}$ Although the kappa values were suboptimal, it was felt that this principally reflected an inevitable variation in interpretation, which is in reality a constant feature of joint decision making involving doctors and nurses. The kappa values provided evidence, on the other hand, of a satisfactory degree of common understanding of the case definition. This in turn made it possible to seek consensus judgements during the main study, which mirrors the way such decisions would be made in practice. The response rates to all phases of the study were very satisfactory.

In terms of validity, it was disappointing that as many as $10 \%$ of those selected for the patient hotel were judged unsuitable by a medically qualified member of the research team. As a result the confidence limits that can be placed on this proportion are wider (in absolute terms) than anticipated. The need for patient mobility was not sufficiently appreciated by the clinicians in these cases. The upper and lower confidence limits have been incorporated into the bed number estimates to show the possible impact of sampling error.

It is possible to make a direct translation from the number of suitable patients in our study to patient hotel bed numbers, as in table VI. The quantity of underlying interest in bed planning is the number, or porportion, of bed days occupied by the relevant category of patient. The seven, repeated cross sectional surveys of patients in this study should give an unbiased estimate of the proportion of bed days occupied by suitable patients. The only qualification is that the mean length of stay in the patient hotel should not differ from the mean residual length of stay if the patients concerned were to remain in the hospital.

This study is unusual in providing specific information about suitability for a defined model of care, for a wide range of specialities. Clinical staff have been closely involved in making judgements, the intention being that actual use of the hotel, when opened, should closely mirror these hypothetical assessments. Previous
Table VI Number of patient hotel (PH) beds required

\begin{tabular}{|c|c|c|c|c|c|c|c|c|}
\hline \multirow[b]{2}{*}{$\begin{array}{l}\text { Census } \\
\text { day }\end{array}$} & \multirow[b]{2}{*}{$\begin{array}{l}\text { Response } \\
(a / b)\end{array}$} & \multirow[b]{2}{*}{$\begin{array}{l}\text { Suitable for } \\
P H(c)\end{array}$} & \multirow[b]{2}{*}{$\begin{array}{l}\text { Suitable for } \\
P H \\
\text { (factored up }) \\
(d)=\left(c \times b^{\prime} a\right)\end{array}$} & \multicolumn{3}{|c|}{ Allowance for validation } & \multirow[b]{2}{*}{$\begin{array}{l}\text { Relatives } \\
\text { and ward } \\
\text { attenders } \\
\text { (h) }\end{array}$} & \multirow[b]{2}{*}{$\begin{array}{l}\text { Total PH beds point } \\
\text { estimate }(e+h) \\
\text { (lower limit }(g+h) \\
\text { upper limit }(f+h))\end{array}$} \\
\hline & & & & $\begin{array}{l}10 \cdot 3 \% \\
\text { unsuitable (e) } \\
(d-(d \times 0 \cdot 103))\end{array}$ & $\begin{array}{l}4 \cdot 2 \% \\
\text { unsuitable } \\
\text { (lower } C L)(f) \\
(d-(d \times 0 \cdot 042)) \\
\end{array}$ & $\begin{array}{l}20 \cdot 1 \% \\
\text { unsuitable } \\
\text { (upper } C L)(g) \\
(d-(d \times 0 \cdot 201))\end{array}$ & & \\
\hline 1 & $621 / 645$ & 72 & 75 & 67 & 72 & 60 & 23 & $90(83,95)$ \\
\hline 2 & $556 / 642$ & 63 & 73 & 65 & 70 & 58 & 9 & $74(67,79)$ \\
\hline 3 & $516 / 693$ & 50 & 67 & 60 & 64 & 54 & 15 & $75(69,79)$ \\
\hline 4 & $574 / 677$ & 59 & 70 & 63 & 67 & 56 & 3 & $66(59,70)$ \\
\hline 5 & $605 / 626$ & 76 & 79 & 71 & 76 & 63 & 14 & $85(77,90)$ \\
\hline 6 & $548 / 590$ & 39 & 42 & 38 & 40 & 34 & 20 & $58(54,60)$ \\
\hline & $552 / 642$ & 46 & 54 & 49 & 52 & 43 & 8 & $57(51,60)$ \\
\hline Total & $3972 / 4515$ & 405 & 460 & 413 & 441 & 368 & 92 & $505(460,533)$ \\
\hline Mean & $567 / 645$ & 58 & 66 & 59 & 63 & 53 & 13 & $72(66,76)$ \\
\hline
\end{tabular}




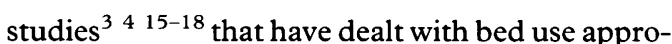
priateness have generally identified patients not requiring acute care rather than identifying numbers suitable for other defined provision. Most have measured the extent of inappropriateness without contributing to the search for specific solutions. Anderson $e t$ al ${ }^{1}$ did, however, find that a similar proportion $(14.5 \%)$ of bed days in three specialities (general surgery, medicine, and geriatrics) were occupied by patients who did not require nursing care and were waiting in hospital "for medical reasons". It is reasonable to equate this group with that under scrutiny in our study.

This study has also shown the residual potential (amounting to a mean of 17 patients per day) for day treatment and investigation (table I) even in a hospital with substantial day facilities. These facilities were being refurbished during the early part of this study, but day treatment continued in ward areas and, furthermore, there was no discernible change when the day unit was reinstated.

Although a high proportion of patients were discharged either on the same day or the day after being judged fit, a sizeable minority $(16.5 \%)$ remained a further two to seven days. It is likely that a substantial proportion of those remaining beyond seven days showed some change in their medical condition. The two to seven day delay group would have accounted for approximately $3-4 \%$ of the total occupied bed days in that defined period, equivalent in this hospital to about 22 beds. The discharge assessment was a consensus judgement between a doctor and nurse. This delay in discharge may reflect either a lack of true commitment, by one or other party, to that judgement, or a failure of routine discharge mechanisms. These data cannot distinguish between these possibilities.

The NHS is increasingly refocusing upon the central purposes of a health care system. ${ }^{19} 20$ Goals and objectives are being formulated from which service delivery options should flow in a complicated but nonetheless logical fashion. Capital planning and bed provision is properly being relegated to the role of a tool in, rather than the determinant of, health care delivery.

The findings of this study suggest that in this typical 850 bed hospital an average of 98 beds could be freed by a combination of more appropriate provision (patient hotel, increased day care) and more timely discharge arrangements. These findings based on precise research, are more valuable than previous cruder estimates. ${ }^{6}{ }^{10}$ The resources potentially released for more appropriate purposes are substantial, amounting to an estimated $£ 2.7$ million per annum in a 1000 bed hospital. ${ }^{6}$

We wish to thank the following for their invaluable assistance: the members of the Project Steering Group (Mr D Crosby, Mr A Evans, Dr J H Jones, Dr B Lawrie, Mr P Morris, Mrs Y Peters, and Dr D Sastry); all medical, nursing, and clerical staff of the University Hospital of Wales for help in data collection; Mrs Gaynor Thorne for secretarial assistance; and South Glamorgan Health Authority for funding.

1 Anderson P, Meara J, Brodhurst S, Attwood S, Timbrell M Gatherer A. Use of hospital beds: a cohort study of admissions to a provincial teaching hospital. BMF 1988 297: $910-12$.

2 Beech R, Challah S, Ingram RH. Impact of cuts in acute beds on services for patients. BMF 1987; 294: 685-8.

3 Murphy FW. Blocked beds. BMF 1977; 1: 1395-6.

4 Torrance N, Lawson JAR, Hogg B, Knox JDE. Acute admissions to medical beds. $\mathcal{F} R$ Coll Gen Pract 1972; 22: 211-19.

5 Marks L. Home and hospital care: redrawing the boundaries. London: King's Fund Institute, 1991.

London: King's Fund Institute, 1991. Davies C. Enjoy your stay at $1990 ; 100 ; 1316-7$.

fournal $1990 ; 100 ; 1316-7$.
Anonymous. Birmingham may adopt patient hotels concept. Anonymous. Birmingham may adopt patient
Health Service fournal 1991; 101 (5238):7.

8 Hospital's "hotel" beds plan raises patient care fears The Observer; December 22, 1991

9 Guy's Hospital may care for patients in "hotel". The Observer: January 26, 1992.

10 Audit Commission. Lying in wait: the use of medical beds in acute hospitals. London: HMSO, 1992

11 Bradley-Davies ML, Groneman S. The hotel alternative program: a new trend for cost containment. ANNA fournal 1987; 14: 22-4.

12 Pesmen S, Medical inns keep patients, profits near. Modern Healthcare $1989 ; 19: 72-4$.

13 Siegel S, Castellan NJ. Nonparametric statistics for the behavioural sciences. New York: McGraw-Hill, 1988.

14 Koran LM. The reliability of clinical methods, data and judgements. New Engl f Med 1975; 293: 695-701.

15 Zudgements. New Engl JW. Groomes EW. An observer reliability study of physicians' and nurses' decisions in utilisation review of physicians' and nurses' decisions in utilisation re

16 Zimmer JG. An evaluation of observer variability in a hospital bed utilisation study. Med Care 1967; 5: 221-33. 7 Gospital bed utilisation study. Med Care 1967; 5: 221-33. Gertman PM, Restuccia J. The appropria

protocol. Med Care 1981; 19: 855-70. 8 Rosser RM. The reliability and application of clinical judgement in evaluating the use of hospital beds. Med Care 1976; 14: 39-48.

19 Department of Health. The health of the nation. London HMSO, 1992, (Cmnd 1986).

20 The Welsh Office. Strategic intent and direction for the NHS in Wales. Cardiff: Welsh Office, 1989. 